\title{
Early insulin sensitivity after restrictive bariatric surgery, inconsistency between HOMA-IR and steady- state plasma glucose levels.
}

Citation for published version (APA):

van Dielen, F. M., Nijhuis, J., Rensen, S. S., Schaper, N. C., Wiebolt, J., Koks, A., Prakken, F. J., Buurman, W. A., \& Greve, J. W. (2010). Early insulin sensitivity after restrictive bariatric surgery, inconsistency between HOMA-IR and steady-state plasma glucose levels. Surgery for Obesity and Related Diseases, 6(4), 340-344. https://doi.org/10.1016/j.soard.2009.11.011

Document status and date:

Published: 01/01/2010

DOI:

10.1016/j.soard.2009.11.011

Document Version:

Publisher's PDF, also known as Version of record

\section{Document license:}

Taverne

Please check the document version of this publication:

- A submitted manuscript is the version of the article upon submission and before peer-review. There can be important differences between the submitted version and the official published version of record.

People interested in the research are advised to contact the author for the final version of the publication, or visit the DOI to the publisher's website.

- The final author version and the galley proof are versions of the publication after peer review.

- The final published version features the final layout of the paper including the volume, issue and page numbers.

Link to publication

\footnotetext{
General rights rights.

- You may freely distribute the URL identifying the publication in the public portal. please follow below link for the End User Agreement:

www.umlib.nl/taverne-license

Take down policy

If you believe that this document breaches copyright please contact us at:

repository@maastrichtuniversity.nl

providing details and we will investigate your claim.
}

Copyright and moral rights for the publications made accessible in the public portal are retained by the authors and/or other copyright owners and it is a condition of accessing publications that users recognise and abide by the legal requirements associated with these

- Users may download and print one copy of any publication from the public portal for the purpose of private study or research.

- You may not further distribute the material or use it for any profit-making activity or commercial gain

If the publication is distributed under the terms of Article $25 \mathrm{fa}$ of the Dutch Copyright Act, indicated by the "Taverne" license above, 
Original article

\title{
Early insulin sensitivity after restrictive bariatric surgery, inconsistency between HOMA-IR and steady-state plasma glucose levels
}

\author{
Francois M. H. van Dielen, M.D., Ph.D. ${ }^{a}$, Jeroen Nijhuis, M.D., Ph.D. ${ }^{\mathrm{a}, *}$, \\ Sander S. M. Rensen, Ph.D. ${ }^{\mathrm{a}}$, Nicolaas C. Schaper, M.D., Ph.D. ${ }^{\mathrm{b}}$, Janneke Wiebolt, M.D. ${ }^{\mathrm{a}}$, \\ Afra Koks, M.D. ${ }^{a}$, Fred. J. Prakken, M.D. ${ }^{a}$, Wim A. Buurman, Ph.D. ${ }^{a}$, \\ Jan Willem M. Greve, M.D., Ph.D. ${ }^{a}$ \\ ${ }^{a}$ Nutrition and Toxicology Research Institute Maastricht (NUTRIM), Department of General Surgery, Maastricht University/University Hospital \\ Maastricht, Maastricht, The Netherlands \\ ${ }^{b}$ Department of Internal Medicine, Maastricht University/University Hospital Maastricht, Maastricht, The Netherlands \\ Received July 9, 2009; revised November 1, 2009; accepted November 18, 2009
}

\begin{abstract}
Background: The low-grade inflammatory condition present in morbid obesity is thought to play a causative role in the pathophysiology of insulin resistance (IR). Bariatric surgery fails to improve this inflammatory condition during the first months after surgery. Considering the close relation between inflammation and IR, we conducted a study in which insulin sensitivity was measured during the first months after bariatric surgery. Different methods to measure IR shortly after bariatric surgery have given inconsistent data. For example, the Homeostatic Model Assessment of Insulin Resistance (HOMA-IR) levels have been reported to decrease rapidly after bariatric surgery, although clamp techniques have shown sustained insulin resistance. In the present study, we evaluated the use of steady-state plasma glucose (SSPG) levels to assess insulin sensitivity 2 months after bariatric surgery.

Methods: Insulin sensitivity was measured using HOMA-IR and SSPG levels in 11 subjects before surgery and at 26\% excess weight loss (approximately 2 months after restrictive bariatric surgery). Results: The SSPG levels after $26 \%$ excess weight loss did not differ from the SSPG levels before surgery $(14.3 \pm 5.4$ versus $14.4 \pm 2.7 \mathrm{mmol} / \mathrm{L})$. In contrast, the HOMA-IR values had decreased significantly $(3.59 \pm 1.99$ versus $2.09 \pm 1.02)$.

Conclusion: During the first months after restrictive bariatric surgery, we observed a discrepancy between the HOMA-IR and SSPG levels. In contrast to the HOMA-IR values, the SSPG levels had not improved, which could be explained by the ongoing inflammatory state after bariatric surgery. These results suggest that during the first months after restrictive bariatric surgery, HOMA-IR might not be an adequate marker of insulin sensitivity. (Surg Obes Relat Dis 2010;6:340-346.) (C) 2010 American Society for Metabolic and Bariatric Surgery. All rights reserved.
\end{abstract}

Keywords: Morbid obesity; Insulin resistance; Postoperative; Weight loss

Bariatric surgery is considered to be the best treatment of morbid obesity and its co-morbidities [1]. In the long term, bariatric surgery not only results in improved body weight,

\footnotetext{
*Correspondence: Jeroen Nijhuis, M.D., Ph.D., Department of General Surgery, Maastricht University/University Hospital Maastricht, P.O. Box 616, Maastricht 6200 MD, The Netherlands.

E-mail: jeroennijhuis@ hotmail.com
}

but also reduces the low-grade inflammatory condition associated with morbid obesity [2]. Extensive evidence has shown that this low-grade inflammatory condition plays a causative role in the pathophysiology of insulin resistance (IR) [3-7]. For example, treatment of subjects with IR using the anti-inflammatory drug acetylsalicylic acid resulted in improved insulin sensitivity [8,9]. In addition, previous studies have shown increased insulin sensitivity 
and reduced inflammation in the long term after bariatric surgery $[10,11]$.

However, previous data have shown that despite substantial weight loss, several parameters of the low-grade inflammatory condition did not decrease during the first months after bariatric surgery. The plasma levels of acute phase proteins and the tumor necrosis factor (TNF)- $\alpha$ receptor, as well as markers of endothelial activation and adiponectin and resistin levels, remained unchanged at 3 months after surgery $[10,12]$. Therefore, IR is not expected to decline during the first months after bariatric surgery.

Insulin sensitivity can be measured using clamp techniques, intravenous or oral glucose tolerance tests, and validated models such as the Homeostatic Model Assessment of Insulin Resistance (HOMA-IR) and Quantitative Insulin Sensitivity Check Index. The euglycemic hyperinsulinemic clamp technique is the reference standard, but other techniques such as the steady state plasma glucose (SSPG) test have been developed that are less likely to result in hypoglycemia. Measuring the SSPG levels is a well-validated alternative introduced by Shen et al. [13] and Reaven and Olefsky [14]. It is a method that has been used for $>35$ years to measure insulin sensitivity and correlates strongly $(r>.90)$ with the more commonly used euglycemic hyperinsulinemic clamp technique. The SSPG test is an insulin suppression test that determines a steady state of plasma glucose concentration as a measure for insulin-mediated glucose uptake $[13,14]$.

Many studies have shown that the HOMA-IR values decrease in the first months after bariatric surgery [15-17]. However, studies using the clamp techniques directly after bariatric surgery have been limited and inconsistent, showing both decreased IR and no change in IR $[18,19]$. This led us to investigate insulin sensitivity before and approximately 2 months after bariatric surgery, when patients had lost $26 \%$ of their excess weight, using both the HOMA-IR and SSPG levels.

\section{Methods}

A total of 11 consecutive patients who were admitted to the surgical department of the University Hospital Maastricht for restrictive surgical treatment of morbid obesity participated in the present study. Of the 11 patients, 7 underwent vertical banded gastroplasty and 4 underwent LapBand surgery. The patients were otherwise healthy according to their history, clinical examination, and routine laboratory test findings. In particular, none of the studied patients had evidence of diabetes mellitus or inflammatory disease or were taking medications known to influence the glucose metabolism or inflammation. The morbidly obese patients underwent the SSPG test before gastric restrictive surgery (baseline) and after 26\% excess weight loss (EWL). During the 2-month period, no significant band adjustments were performed in the LapBand patients. The characteristics
Table 1

Characteristics of study population

\begin{tabular}{llc}
\hline Variable & $\begin{array}{l}\text { Preoperative } \\
(\mathrm{n}=11)\end{array}$ & $\begin{array}{l}\text { At 26\% EWL } \\
(\mathrm{n}=11)\end{array}$ \\
\hline Gender & & \\
$\quad$ Female & 9 & 9 \\
$\quad$ Male & 2 & 2 \\
Age (yr) & $40.4 \pm 7.6$ & $40.4 \pm 7.6$ \\
Body mass index $\left(\mathrm{kg} / \mathrm{m}^{2}\right)$ & $44.6 \pm 3.3$ & $39.4 \pm 3.4^{*}$ \\
Waist/hip ratio & $0.97 \pm 0.08$ & $0.93 \pm 0.1$ \\
Weight loss $(\mathrm{kg})$ & & $14.9 \pm 3.3$ \\
Fasting glucose (mmol/L) & $5.4 \pm 0.6$ & $5.5 \pm 0.7$ \\
Fasting insulin (mU/L) & $14.8 \pm 7.8$ & $7.4 \pm 4.5^{*}$ \\
HOMA-IR & $3.59 \pm 1.99$ & $2.09 \pm 1.02^{*}$ \\
Postoperative interval (d) & & $53 \pm 26$ \\
\hline
\end{tabular}

EWL $=$ excess weight loss; HOMA-IR $=$ Homeostatic Model Assessment of Insulin Resistance.

$* P<.05$ compared with preoperatively.

of the study population are presented in Table 1 . The ethical committee of the University Hospital Maastricht (Maastricht, The Netherlands) approved the study. All patients gave written informed consent.

\section{SSPG test and HOMA-IR}

Insulin sensitivity was studied by determining the SSPG levels. First, the endogenous insulin production by the pancreas was suppressed using octreotide (Sandostatin, Novartis Pharma B.V., Arnhem, The Netherlands), given as bolus followed by a continuous infusion. Next, glucose and insulin were infused at a fixed rate. At 150-180 minutes, the plasma insulin and glucose levels had reached a steady state. These levels are termed the steady state plasma insulin (SSPI) and SSPG levels. The SSPG level is a reflection of insulin-mediated glucose uptake and a marker of insulin sensitivity. Thus, it is essential for the preoperative SSPI levels to be comparable to the SSPI levels at 26\% EWL.

After a 12-hour overnight fast, the body weight and body height were measured. The patients were measured in the supine position in a hospital bed. Catheters were placed in both antecubital veins to enable infusion of glucose, insulin, and octreotide, as well as venous blood sampling. During an acclimatization period of 30 minutes, an automatic blood pressure measurement (Dinamap, Criticon, Tampa, FL) was taken. Octreotide, a somatostatin analogue, was administered intravenously using a syringe infusion pump (Treonic IP4, Vickers Medical, Sidcap Kent, England) at $5.0 \mu \mathrm{g} / \mathrm{min}$, preceded by a bolus of $25 \mu \mathrm{g}$. In both the pre- and postoperative measurements of SSPG, the same octreotide concentration was used, decreasing the chance of confounding the results from high octreotide plasma concentrations. Insulin (Actrapid, Novo-Nordisk, Bagsærd, Denmark) was infused at a rate of $25 \mathrm{mU} / \mathrm{m}^{2} / \mathrm{min}$ using a second syringe pump. Glucose was infused using a volumetric pump (IVAC 591, IVAC, San Diego, CA) at $240 \mathrm{mU} / \mathrm{m}^{2} / \mathrm{min}$. Before the test and at different points during the test, venous blood samples 
were taken. The mean plasma glucose level at 150, 160, 170, and 180 minutes was defined as the SSPG level. The SSPG levels provide an indirect measure of IR [20].

Plasma glucose was determined using a glucose oxidase method (YSI model 2300 Stat, Yellow Springs Industries, Yellow Springs, $\mathrm{OH}$ ). The blood samples for determining the inflammatory mediators and insulin were immediately put on melting ice, and the plasma was prepared by centrifugation at $1400 \mathrm{~g}$ for 10 minutes at $4^{\circ} \mathrm{C}$. The plasma was centrifuged again at $2700 \mathrm{~g}$ for 10 minutes at $4^{\circ} \mathrm{C}$, and the recovered plasma was stored in aliquots at $-80^{\circ} \mathrm{C}$ until measurement.

HOMA-IR is a mathematical model by which insulin sensitivity can be assessed using the fasting glucose and insulin plasma levels [21].

\section{Reagents, materials, and assays}

The plasma concentrations of soluble TNF- $\alpha$ receptors, leptin, lipopolysaccharide-binding protein, $\mathrm{C}$-reactive protein, $\alpha_{1}$-acid glycoprotein, and insulin were measured using sandwich enzyme-linked immunosorbent assays. The TNF- $\alpha$ receptors (55 and 75), leptin, lipopolysaccharide-binding protein, C-reactive protein, and $\alpha_{1}$-acid glycoprotein were measured, as described previously [10]. The plasma insulin concentrations were measured using a commercially available enzyme-linked immunosorbent assay (Mercodia AB, Uppsala, Sweden).

All plasma samples were measured in the same run, except for the plasma insulin concentrations. When the plasma concentrations exceeded the upper detection limit of the assay, the samples were diluted more and analyzed in a separate run with an overlap. The intra- and interassay coefficients of variance of the assays were $<10 \%$.

\section{Statistical analysis}

The data are expressed as the mean \pm standard deviation. The Wilcoxon sign-rank test was used to analyze the differences. $P<.05$ was considered statistically significant.

\section{Results}

Effect of weight loss on metabolic and inflammatory mediators

After bariatric surgery, $26 \% \pm 4 \%$ EWL was reached within $53 \pm 26$ days, resulting in a body mass index decrease from $46.2 \pm 5.6 \mathrm{~kg} / \mathrm{m}^{2}$ (preoperatively) to $40.7 \pm 4.1$ $\mathrm{kg} / \mathrm{m}^{2}$ postoperatively. The mean percentage weight loss was $11.6 \% \pm 1.6 \%$ for the study subjects.

As listed in Table 1, the fasting plasma glucose levels before surgery were in the normal range $(<5.6 \mathrm{mmol} / \mathrm{L})$, with increased fasting plasma insulin levels $(14.8 \pm 7.8$ $\mathrm{mU} / \mathrm{L}$; normal $<12 \mathrm{mU} / \mathrm{L}$ ) resulting in an increased HOMA-IR $(3.59 \pm 1.99)$. The fasting plasma glucose levels at $26 \%$ EWL were similar to the preoperative values. In
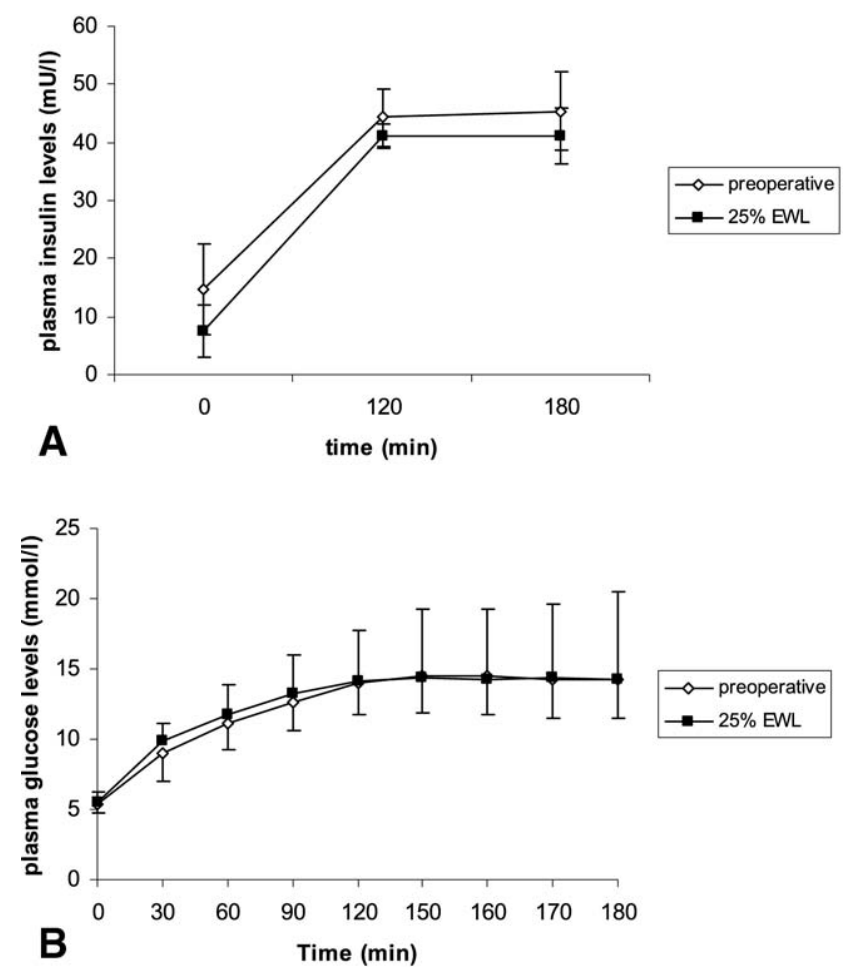

Fig. 1. Pre- and postoperative SSPI and SSPG levels. (A) Preoperative SSPI values did not significantly differ from those measured at $26 \%$ EWL $(14.4 \pm 2.7$ versus $14.3 \pm 5.4 \mathrm{mmol} / \mathrm{L})$. Therefore, pre- and postoperative SSPG levels could be compared. (B) SSPG levels did not decrease in first months after restrictive bariatric surgery, indicating that during the first months after surgery, insulin sensitivity did not improve.

contrast, the fasting insulin plasma levels and HOMA-IR decreased after surgery $(7.4 \pm 4.5 \mathrm{mU} / \mathrm{L}$ and $2.09 \pm 1.02$, respectively; $P<.05)$.

Fig. 1 shows the pre- and postoperative SSPI and SSPG levels. Because the SSPI levels were not significantly different pre- and postoperatively $(P=.76)$, the pre- and postoperative SSPG levels could be compared. Preoperatively, the glucose levels were increased during the SSPG test to reach an SSPG concentration of $14.4 \pm 2.7 \mathrm{mmol} / \mathrm{L}$. This concentration was much greater than the SSPG levels found in healthy subjects $(4.1 \pm 0.4 \mathrm{mmol} / \mathrm{L})$, indicating reduced preoperative insulin sensitivity in our morbidly obese subjects. These data represent the lower 30th percentile of IR as measured by Yeni-Komshian et al. [22] in 490 healthy volunteers.

The mean SSPG concentration before surgery was not significantly different from the mean SSPG concentration after bariatric surgery at $26 \%$ EWL $(14.3 \pm 5.3 \mathrm{mmol} / \mathrm{L})$, suggesting sustained IR.

Because inflammation is known to contribute to IR, we also investigated the plasma levels of inflammatory molecules before and after surgery. In line with earlier data [10], the plasma leptin levels had decreased significantly, but the circulating levels of acute phase proteins (C-reactive protein, $\alpha_{1}$-acid glycoprotein, and lipopolysaccharide-binding 
Table 2

Levels of inflammatory mediators at $\mathrm{t}=0$ during SSPG test

\begin{tabular}{lcl}
\hline Variable & $\begin{array}{l}\text { Preoperatively } \\
(\mathrm{n}=11)\end{array}$ & $\begin{array}{l}\text { At 26\% EWL } \\
(\mathrm{n}=11)\end{array}$ \\
\hline Leptin $(\mathrm{ng} / \mathrm{mL})$ & $67.0 \pm 31.5$ & $26.9 \pm 14.3^{*}$ \\
CRP $(\mu \mathrm{g} / \mathrm{mL})$ & $20.3 \pm 12.1$ & $21.9 \pm 17.1$ \\
AGP $(\mathrm{ng} / \mathrm{mL})$ & $12.1 \pm 7.7$ & $10.3 \pm 5.2$ \\
LBP $(\mu \mathrm{g} / \mathrm{mL})$ & $36.2 \pm 16.9$ & $35.1 \pm 11.6$ \\
Soluble TNFR55 $(\mathrm{ng} / \mathrm{mL})$ & $0.6 \pm 0.21$ & $0.67 \pm 0.2$ \\
Soluble TNFR75 $(\mathrm{ng} / \mathrm{mL})$ & $1.07 \pm 0.43$ & $1.34 \pm 0.47$ \\
\hline
\end{tabular}

SSPG $=$ steady-state plasma glucose $;$ EWL $=$ excess weight loss; $\mathrm{CRP}=\mathrm{C}$-reactive protein; $\mathrm{AGP}=\alpha_{1}$-acid glycoprotein; $\mathrm{LBP}=$ lipopolysaccharide-binding protein; $\mathrm{TNF}=$ tumor-necrosis factor.

$* P<.05$ compared with preoperatively.

protein) and TNF- $\alpha$ receptors had not changed, despite the substantial weight loss at 26\% EWL (Table 2). A separate analysis of the LapBand and vertical banded gastroplasty study subjects did not show differences in outcome.

\section{Discussion}

Considering the close relationship between inflammation and IR, the insulin sensitivity was measured during the first months after surgery, which is characterized by ongoing inflammation. Previous data published by our group have indicated that in the long term after bariatric surgery (3 years postoperatively, 70\% EWL), the SSPG levels improve [23]. However, the results of the present study have shown that the SSPG levels had not decreased at 2 months after surgery, indicating that the patients still experienced IR despite their substantial weight loss. Similar results were obtained in a study using the euglycemic hyperinsulinemic clamp technique to measure insulin sensitivity after gastric bypass surgery and biliopancreatic diversion (BPD) [18]. Approximately 5 months postoperatively, the IR had not decreased in the gastric bypass group. In contrast, insulin sensitivity had significantly improved at 5 months after BPD. Insulin sensitivity will have already been ameliorated within 4 weeks after BPD [19]. Because gastric bypass surgery is considered restrictive, with only a minor malabsorptive component [24], the results of the present study support the concept that techniques mainly using restriction, unlike malabsorptive procedures, do not immediately reduce peripheral insulin sensitivity. It is thought that incretins such as glucagon-like peptide-1 (GLP-1) and gastrointestinal polypeptide play a central role in the observed differences [19]. Malabsorptive surgery results in bypass of the foregut, as well as exposure of the distal ileum to undigested food. Consequently, the secretion of gastrointestinal polypeptide and GLP-1 is altered [25]. Both gastrointestinal polypeptide and GLP-1 are known to increase insulin sensitivity and secretion [26]; therefore, malabsorptive surgery is thought to be more effective in increasing insulin sensitivity than purely restrictive procedures. This has been illustrated by Laferrere et al. [27], who compared the oral glucose tolerance after gastric bypass surgery to the glucose tolerance after a 1 month of a very low calorie diet. Gastric bypass resulted in lower postprandial glucose levels, despite comparable weight loss. This difference could be explained by the greater levels of GLP-1 after gastric bypass surgery.

A possible explanation for the unchanged SSPG levels in the first months after bariatric surgery, such as were observed in the present study, could be insufficient weight loss. At 26\% EWL, the subjects had lost approximately 15 $\mathrm{kg}$, but the body mass index remained in the morbid obese spectrum $\left(39.4 \mathrm{~kg} / \mathrm{m}^{2}\right)$. Thus, it appears that peripheral insulin sensitivity only starts to improve after a certain set point, which was not reached in our study population. However, studies of obese individuals restricted to a very low calorie diet have shown increased insulin sensitivity using clamp techniques. These subjects lost a significant amount of weight, although not as much as our study population. An explanation for this effect could be that the major surgical procedure influences insulin sensitivity, for example, by provoking other inflammatory processes. In line with previous studies from our group, the inflammatory condition did not improve during the first 2 months after bariatric surgery in the present study $[10,12]$. Another explanation relates to the severe catabolic state associated with substantial weight loss in the first months after bariatric surgery. Thus, several studies have shown decreased insulin sensitivity in adipose tissue during fasting $[28,29]$. The inconsistency of restrictive versus malabsorptive bariatric procedures with respect to their early effects on insulin sensitivity should be the subject of future research.

In contrast to the unchanged insulin sensitivity as measured by SSPG testing in the first months after surgery, the HOMA-IR levels had decreased significantly at that point. This was mainly because of reduced fasting plasma insulin levels after surgery, although the circulating fasting plasma glucose levels had not changed significantly during the 2 -month period. These results indicate that during the first months after bariatric surgery, the HOMA-IR index might not be valid as a marker of insulin sensitivity.

The observed differences between HOMA-IR and SSPG might be explained by the storage capacity of the liver for macronutrients. In insulin-resistant morbidly obese patients without type 2 diabetes, increased fasting plasma insulin levels and normal or slightly increased fasting plasma glucose levels will be found. This is thought to be related to the increased gluconeogenesis during the fasting period in insulin-resistant hepatocytes and results in elevated insulin production by the pancreas [30]. We suggest that during rapid weight loss, the hepatocytes might lose the stored macronutrients earlier than do the skeletal muscle cells or adipocytes, leading to increased hepatic insulin sensitivity compared to the skeletal muscle or adipocytes, resulting in reduced fasting plasma insulin levels. Perhaps this could also explain the difference observed after BPD and gastric 
bypass with respect to the improvement of insulin sensitivity postoperatively. The more rigorous weight loss occurring after BPD could force triglycerides out of the muscle and adipose tissue more rapidly compared with other types of bariatric surgery. The SSPI levels did not decrease, indicating that the insulin clearance capacity of the liver was still impaired and, thus, not paralleling the decline in gluconeogenesis. Unpublished data from our group have indicated decreased SSPI levels at 50\% EWL, demonstrating increased insulin clearance by the liver.

\section{Conclusion}

In the present small study of nondiabetic, insulin-resistant patients, we found that IR as measured by SSPG did not improve, despite substantial weight loss, in the first months after restrictive bariatric surgery, paralleling the sustained lowgrade inflammatory condition. In contrast, the HOMA-IR values decreased during the first months after restrictive bariatric surgery, suggesting that the HOMA-IR index is not an adequate marker of insulin sensitivity after restrictive bariatric surgery.

\section{Disclosures}

The authors have no commercial associations that might be a conflict of interest in relation to this article.

\section{References}

[1] Buchwald H, Avidor Y, Braunwald E, et al. Bariatric surgery: a systematic review and meta-analysis. JAMA 2004;292:1724-37.

[2] Cottam DR, Mattar SG, Barinas-Mitchell E, et al. The chronic inflammatory hypothesis for the morbidity associated with morbid obesity: implications and effects of weight loss. Obes Surg 2004;14: $589-600$

[3] Hanley AJ, Festa A, D'Agostino RB Jr, et al. Metabolic and inflammation variable clusters and prediction of type 2 diabetes: factor analysis using directly measured insulin sensitivity. Diabetes 2004; 53:1773-81.

[4] Xu H, Barnes GT, Yang Q, et al. Chronic inflammation in fat plays a crucial role in the development of obesity-related insulin resistance. J Clin Invest 2003;112:1821-30.

[5] Leinonen E, Hurt-Camejo E, Wiklund O, et al. Insulin resistance and adiposity correlate with acute-phase reaction and soluble cell adhesion molecules in type 2 diabetes. Atherosclerosis 2003;166:387-94.

[6] Dandona P, Aljada A, Bandyopadhyay A. Inflammation: the link between insulin resistance, obesity and diabetes. Trends Immunol 2004;25:4-7.

[7] Shoelson SE, Lee J, Goldfine AB. Inflammation and insulin resistance. J Clin Invest 2006;116:1793-801.

[8] Hundal RS, Petersen KF, Mayerson AB, et al. Mechanism by which high-dose aspirin improves glucose metabolism in type 2 diabetes. J Clin Invest 2002;109:1321-6.

[9] Yuan M, Konstantopoulos N, Lee J, et al. Reversal of obesity- and diet-induced insulin resistance with salicylates or targeted disruption of Ikkbeta. Science 2001;293:1673-7.
[10] van Dielen FM, Buurman WA, Hadfoune M, Nijhuis J, Greve JW. Macrophage inhibitory factor, plasminogen activator inhibitor-1, other acute phase proteins, and inflammatory mediators normalize as a result of weight loss in morbidly obese subjects treated with gastric restrictive surgery. J Clin Endocrinol Metab 2004;89:4062-8.

[11] Hansen EN, Torquati A, Abumrad NN. Results of bariatric surgery. Annu Rev Nutr 2006;26:481-511.

[12] Nijhuis J, van Dielen FM, Fouraschen SM, et al. Endothelial activation markers and their key regulators after restrictive bariatric surgery. Obesity (Silver Spring) 2007;15:1395-9.

[13] Shen SW, Reaven GM, Farquhar JW. Comparison of impedance to insulin-mediated glucose uptake in normal subjects and in subjects with latent diabetes. J Clin Invest 1970;49:2151-60.

[14] Reaven GM, Olefsky JM. Relationship between heterogeneity of insulin responses and insulin resistance in normal subjects and patients with chemical diabetes. Diabetologia 1977;13:201-6.

[15] Carrasco F, Papapietro K, Csendes A, et al. Changes in resting energy expenditure and body composition after weight loss following Roux-en-Y gastric bypass. Obes Surg 2007;17:608-16.

[16] Morinigo R, Vidal J, Lacy AM, et al. Circulating peptide YY, weight loss, and glucose homeostasis after gastric bypass surgery in morbidly obese subjects. Ann Surg 2008;247:270-5.

[17] Konukoglu D, Uzun H, Firtina S, et al. Plasma adhesion and inflammation markers: asymmetrical dimethyl-L-arginine and secretory phospholipase A2 concentrations before and after laparoscopic gastric banding in morbidly obese patients. Obes Surg 2007;17:672-8.

[18] Muscelli E, Mingrone G, Camastra S, et al. Differential effect of weight loss on insulin resistance in surgically treated obese patients. Am J Med 2005;118:51-7.

[19] Guidone C, Manco M, Valera-Mora E, et al. Mechanisms of recovery from type 2 diabetes after malabsorptive bariatric surgery. Diabetes 2006;55:2025-31.

[20] Pei D, Jones CN, Bhargava R, Chen YD, Reaven GM. Evaluation of octreotide to assess insulin-mediated glucose disposal by the insulin suppression test. Diabetologia 1994;37:843-5.

[21] Kim SH, Abbasi F, Reaven GM. Impact of degree of obesity on surrogate estimates of insulin resistance. Diabetes Care 2004;27: 1998-2002.

[22] Yeni-Komshian H, Carantoni M, Abbasi F, Reaven GM. Relationship between several surrogate estimates of insulin resistance and quantification of insulin-mediated glucose disposal in 490 healthy nondiabetic volunteers. Diabetes Care 2000;23:171-5.

[23] Nijhuis J, van Dielen FM, Schaper NC, et al. Short-term overfeeding induces insulin resistance in weight-stable patients after bariatric surgery. Obes Surg 2008;18:300-5.

[24] Johnson W, DeMaria E. Surgical treatment of obesity. Curr Treat Options Gastroenterol 2006;9:167-4.

[25] Patriti A, Facchiano E, Sanna A, Gulla N, Donini A. The enteroinsular axis and the recovery from type 2 diabetes after bariatric surgery. Obes Surg 2004;14:840-8.

[26] Vilsboll T, Holst JJ. Incretins, insulin secretion and type 2 diabetes mellitus. Diabetologia 2004;47:357-66.

[27] Laferrere B, Teixeira J, McGinty J, et al. Effect of weight loss by gastric bypass surgery versus hypocaloric diet on glucose and incretin levels in patients with type 2 diabetes. J Clin Endocrinol Metab 2008;93:2479-85.

[28] Jensen MD, Haymond MW, Gerich JE, Cryer PE, Miles JM. Lipolysis during fasting: decreased suppression by insulin and increased stimulation by epinephrine. J Clin Invest 1987;79:207-13.

[29] Buijs MM, Burggraaf J, Wijbrandts C, et al. Blunted lipolytic response to fasting in abdominally obese women: evidence for involvement of hyposomatotropism. Am J Clin Nutr 2003;77:544-50.

[30] Groop LC. Insulin resistance: the fundamental trigger of type 2 diabetes. Diabetes Obes Metab 1999;(1 Suppl 1):S1-7. 